\section{The initial distribution volume of glucose and cardiac output in the critically ill}

\author{
Hironori Ishihara MD, Yuki Shimodate MD, \\ Hiroaki Koh MD, Ken-ichi Isozaki MD, \\ Toshihito Tsubo MD, Akitomo Matsuki MD
}

Blood or plasma glucase concentration can be measured accurately and rapidly. However, after a glucose challenge metabolism may modify glucose kinetics, so that glucose has not been used as an indicator for dilution volumetry. To test the hypothesis that the initial distribution volume of glucose (IDVG) reflects cardiac output rather than glucose metabolism in the critically ill, the relationship between IDVG and thermodilution cardiac output was evaluated at 27 points in 13 non-surgical, critically ill patients without congestive heart failure. The IDVG was calculated from incremental plasma glucose concentrations using a one compartment model. Correlations were obtained between the IDVG and cardiac output $(r=0.89$, $n=27, P<0.001$ ), and between the incremental plasma glucose concentrations three minutes afier the injection and the $I D V G(r=0.94, n=27, P<0.001)$. No difference was found between the IDVG with or without continuous insulin infusions. The results indicate that the IDVG reflects cardiac output rather than glucose metabolism in patients without congestive heart failure.

Il est possible de mesurer la concentration plasmatique du glucose avec précision et rapidité. Cependent, après un test $d$ hyperglycémie provoquée, le métabolisme peut modifier le cynétique du glucose. Pour cette raison le glucose n'est pas employé comme indicateur pour l'analyse volumétrique par la méthode de dilution. Pour vérifier l'hypothèse selon laquelle le volume de distribution initial du glucose (VDIG) reflète le débit cardiaque plutôt que le métabolisme glucidique chez le grand mal-

\author{
Key words \\ INTENSIVE CARE: \\ MEASUREMENT TECHNIQUES: cardiac output; \\ METABOLISM: glucose; \\ PHARMACOKINETICS: distribution
}

From: the Department of Anesthesiology, University of Hirosaki, School of Medicine, Hirosaki-Shi, Aomori-Ken, 036 Japan

Address correspondence to: Dr. Ishihara, Current address: Department of Anesthesiology, Southwestern Medical Center, 5323 Harry Hines Blvd., Dallas, Tx 75235. Fax 214/590-6945. Accepted for publication 4th September, 1992. ade, la relation entre VDIG et débit cardiaque est comparée à 27 moments chez 13 grands malades non chirurgicaux sans insuffisance cardiaque. Le VDIG est calculé à partir de concentrations plasmatiques croissantes dans un modèle à compartiment unique. On détermine la corrélation entre VDIG et débit cardiaque $(r=0,89, n=27, P<0,001)$, et entre les concentrations croissantes de glucose plasmatique trois minutes après l'injection et le VDIG ( $r=0,94, n=27, P<0,001)$. Il n'y a pas de différence entre le VDIG mesuré avec ou sans perfusions d'insuline. Les résultats démontrent que le VDIG reflète plus le débit cardiaque que le métabolisme glucidique chez le malade qui ne présente pas dinsuffisance cardiaque.

The initial volume of distribution, or the central compartment of the kinetic description of drug disposition, is that volume in which a drug appears to mix instantaneously before being distributed throughout the remainder of its distribution volume by mixing, flow, and diffusion. ${ }^{1}$ One may speculate that the initial volume of distribution for several drugs is composed mainly of the blood volume and the vessel rich group of tissues, and is determined by cardiac output, regional blood flow and the characteristics of a particular drug. ${ }^{2}$ After an intravenous bolus injection, drug concentrations in blood may be higher in individuals with poor perfusion (e.g., shock) than individuals with better perfusion. ${ }^{3}$ Presumably, cardiac output plays an important role in determining the initial distribution volume of the administered drugs.

Glucose itself appears in the blood physiologically and can be given repeatedly and safely in small amounts even in critically ill patients. Accurate and rapid blood glucose determinations have also become available in the ICU. However, complicating factors involving glucose utilization and/or endogenous glucose production in the body may modify plasma glucose concentrations shortly after a glucose challenge in critically ill patients, and thus the initial distribution volume of glucose (IDVG) may fail to reflect cardiac output.

The purpose of the present study was to test the hypothesis that the IDVG reflects cardiac output in critically ill patients. 


\section{Methods}

\section{Patients}

The protocol was approved by the ethical committee of the University of Hirosaki School of Medicine and each patient gave informed consent. Patients eligible for inclusion in this study had a thermodilution pulmonary artery catheter inserted for clinical indications unrelated to this study. Thirteen non-surgical patients admitted to the general ICU were enrolled. Post-surgical patients, patients with hyperglycaemia (plasma glucose concentration $>25 \mathrm{mmol} \cdot \mathrm{L}^{-1}$ ), or patients with congestive heart failure judged from high pulmonary artery wedge pressure $(>20$ $\mathrm{mmHg}$ ), echocardiogram or chest $x$-ray examination were excluded from the study. Ten patients were on vasoactive drugs and two patients required continuous insulin infusions (Table 1). A total of 27 comparisons between the IDVG and the thermodilution cardiac output were performed.

\section{Methods}

A bolus of $25 \mathrm{ml}$ glucose, $20 \%(5 \mathrm{~g})$, was given over 30 sec through the proximal injectate port of a balloon-tip, flow-directed pulmonary artery catheter (Baxter Model 93A0-741 H-7.5F) which was placed in the right internal jugular vein. A glucose solution (5-22\%) for routine nutritional support was also infused through another central venous line using an electric pump at a constant rate, ranging from $0.1 \mathrm{~g} \cdot \mathrm{kg}^{-1} \cdot \mathrm{hr}^{-1}$ to $0.4 \mathrm{~g} \cdot \mathrm{kg}^{-1} \cdot \mathrm{hr}^{-1}$ at least one hour before the $5 \mathrm{~g}$ glucose challenge and throughout the procedure. The cardiovascular state remained unchanged throughout the procedures, judged from the ECG monitor and direct arterial pressure recordings. Serial blood samples were obtained, through an indwelling radial artery catheter, immediately before and three, five and seven minutes after the glucose injection. Isotonic saline with small amounts of heparin was used to flush the arterial line. Each $2 \mathrm{ml}$ blood sample was collected in a heparinized syringe and plasma was separated immediately by centrifuge. Plasma glucose concentrations were determined using a glucose oxidase method (Fuji Co. Ltd. Glu 20 glucose analyzer). All measurements in the sample were performed in duplicate and averaged. The coefficient of variation was less than $1 \%$ for repeated glucose measurements (range: $4-17 \mathrm{mmol} \cdot \mathrm{L}^{-1}$ ).

\section{Calculation of the IDVG}

The IDVG was calculated using a one compartment model from the excess or incremental plasma glucose decay curve after glucose administration. In the one compartment model, the volume of distribution (Vd) is calculated as follows:

$\mathrm{Vd}=$ Dose $/ \mathrm{C}_{0}$ where Dose $=$ amount of drug administered. $C_{0}=$ initial plasma concentration at time zero after instantaneously distribution, but before the start of elimination ${ }^{2}$. The IDVG was determined using a "least squares" regression technique to find the line of best fit. Residuals were weighted by the inverse-square of the plasma levels. Residual sums of squares (SS) for each curve were examined to evaluate the exponential term of the pharmacokinetic model, ${ }^{4}$ and convergence was assumed when the relative change in the weighted sum of squares was less than $1 \times 10^{-2}$.

\section{Calculation of cardiac output}

Thermodilution cardiac output was measured using a balloon-tip flow-directed pulmonary artery catheter (Baxter Model 93A-741 H-7.5F). The correct position of each catheter was confirmed by pressure tracings and chest $x$-ray examination. Cardiac output was determined by triplicate measurements with $10 \mathrm{ml}$ isotonic saline solution at $\angle 12^{\circ} \mathrm{C}$ injected in less than four seconds immediately after the completion of taking blood samples for glucose determinations. The thermal signals were analyzed using a cardiac output computer (Baxter SAT2). The correlation of variation for repeated measurements was less than $6 \%$.

All equipment including the glucose analyzer were calibrated according to manufacturer's recommendations before and after the study. Numerical data were analyzed for Mean $\pm \mathrm{SD}$ and linear regression. A $P$ value of $<0.05$ identified statistically significant differences.

\section{Results}

The mean plasma glucose concentration immediately before the glucose injection was $10.9 \pm 3.6 \mathrm{mmol} \cdot \mathrm{L}^{-1}$. The concentration reached $14.1 \pm 3.9 \mathrm{mmol} \cdot \mathrm{L}^{-1}$ three minutes after the injection, $13.6 \pm 3.8 \mathrm{mmol} \cdot \mathrm{L}^{-1}$ at five minutes, and $13.3 \pm 3.8 \mathrm{mmol} \cdot \mathrm{L}^{-1}$ at seven minutes.

The residual sums of squares (SS) for each IDVG curve were less than $7 \times 10^{-3}$, which was small enough to allow a one compartment model fit. The IDVG and thermodilution cardiac output varied markedly among the patients, ranging from $3.4 \mathrm{~L}$ to $11.6 \mathrm{~L}$ for the IDVG, and ranging from $1.3 \mathrm{~L} \cdot \mathrm{min}^{-1}$ to $14.0 \mathrm{~L} \cdot \mathrm{min}^{-1}$ for the cardiac output, respectively.

Correlations were obtained between the IDVG and cardiac output ( $r=0.89, P<0.001)$ (Figure 1), and between the incremental glucose concentrations at three minutes postinjection and the IDVG $(\mathrm{r}=0.94, P<$ 0.001 ) (Figure 2). No correlation was found between the IDVG and the preinjection plasma glucose concentration $(r=0.007)$. No difference was found between the IDVG with or without continuous infusions of insulin or vasoactive drugs. 
TABLE Patient characteristics

\begin{tabular}{|c|c|c|c|c|c|c|}
\hline No & Age & $M / F$ & Diagnosis & Comparisons & $\begin{array}{l}\text { Vasoactive drugs } \\
\left(\mu g^{\cdot} \mathrm{kg}^{-1} \cdot \mathrm{min}^{-1}\right)\end{array}$ & $\begin{array}{l}\text { Insulin } \\
\left(U \cdot h r^{-1}\right)\end{array}$ \\
\hline 1 & 45 & $F$ & Post CPR & 1 & NE2, DOA10 & \\
\hline 2 & 21 & $\mathbf{M}$ & Post CPR & 3 & $\mathrm{NE} 0.4-2.0$ & \\
\hline 3 & 26 & $\mathbf{M}$ & Burn & 1 & & \\
\hline 4 & 73 & $F$ & Burn & 2 & DOA3-10 & \\
\hline 5 & 47 & $\mathbf{M}$ & Bum & 5 & & $3-4$ \\
\hline 6 & 39 & $\mathbf{M}$ & Adrenal crisis & 3 & DOA 10 & $2-5$ \\
\hline 7 & 23 & $\mathbf{M}$ & Chest injury & 3 & & \\
\hline 8 & 79 & $\mathbf{M}$ & ARDS & 2 & DOB3 & \\
\hline 9 & 62 & $M$ & Bronchial asthma & 2 & E0.1, Theo8.5 & \\
\hline 10 & 73 & $M$ & Aspiration pneumonitis & 1 & E0.5 & \\
\hline 11 & 75 & $\mathbf{M}$ & AMI & 1 & DOA3 & \\
\hline 12 & 30 & $\mathbf{M}$ & Sepsis & 2 & DOA4 & \\
\hline 13 & 75 & 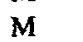 & Hypovolaemia & 1 & DOA 10 & \\
\hline
\end{tabular}

CPR: Cardio-Pulmonary Resuscitation, ARDS: Adult Respiratory Distress Syndrome, AMI: Actute Myocardial Infarction, NE: Norepinephrine, E: Epinephrine, DOA: Dopamine, DOB: Dobutamine, Theo: Theophylline

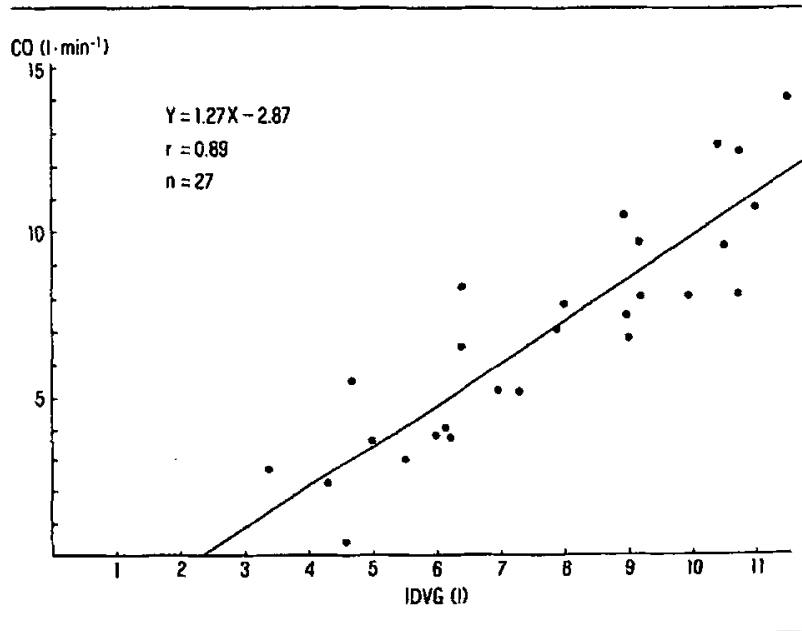

FIGURE I Relationship between the initial distribution volume of glucose (IDVG) and cardiac output (CO)

\section{Discussion}

The present study demonstrated that (1) the residual sums (SS) of each IDVG curve were small enough to allow a one compartment model to be fit, that (2) the IDVG and cardiac output varied markedly among patients, and (3) that a close relationship was observed between the IDVG and thermodilution cardiac output. A one compartment model, however, is a gross over-simplification for most drugs. Models for glucose distribution and utilization in man contain at least two glucose pools, one of which turns over slowly, and is insulin dependent. The other, fast pool, may be divided into blood and an extravascular spaces, and is insulin independent. ${ }^{5,6}$ In the present study all data were collected after the three min-

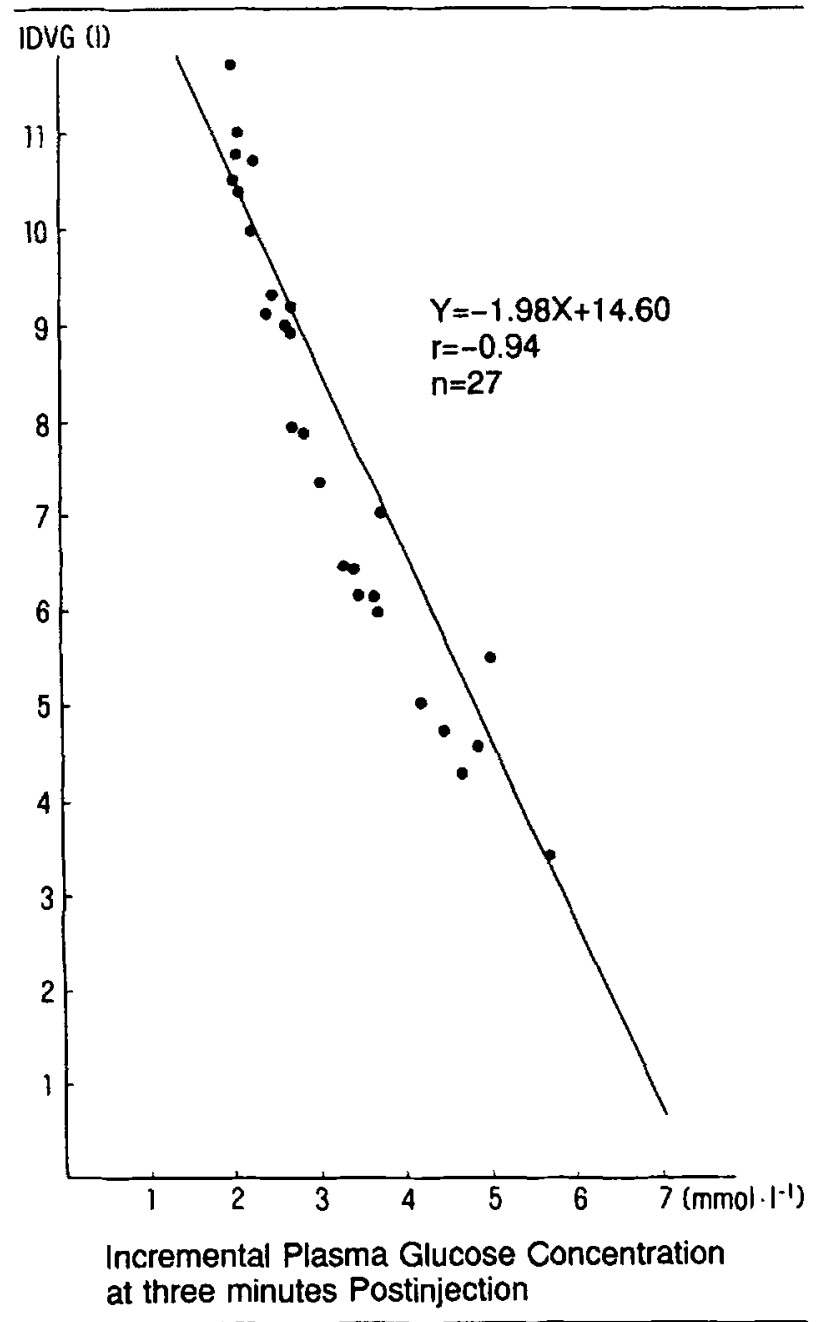

FIGURE 2 Relationship between the incremental plasma glucose concentration at three minutes postinjection and the initial distribution volume of glucose (IDVG) 
utes postinjection in order to ensure that the assumption of complete mixing within the initial distribution volume is satisfied, ${ }^{5,7}$ and postequilibration data within the seven minutes postinjection were fitted to a one compartment model because a fast pool is thought to be uniformly mixed within 10 to $15 \mathrm{~min}^{5}$

The initial distribution volume for several drugs is determined by cardiac output, regional blood flow and the characteristics of a particular drug. ${ }^{2}$ The present results also suggested that cardiac output plays an important role in determining the IDVG. Using a four compartment model proposed by Cunningham and Heath ${ }^{5}$ the fast pool might be $174-188 \mathrm{ml} \cdot \mathrm{kg}^{-1}$ of blood when cardiac output was assigned $100 \mathrm{ml} \cdot \mathrm{kg}^{-1}$.

Although ${ }^{14} \mathrm{C}$ labeled glucose has been reported as an indicator to measure the extracellular water content, ${ }^{8}$ glucose has not been used as an indicator in dilution volumetry because the plasma glucose concentration after glucose injection may be influenced by glucose utilization, endogenous glucose production and the continuous infusion of glucose throughout the procedure. However, these modifying factors might be negligible judged from the observations that (1) no consistent relationship was obtained between the IDVG and the plasma glucose concentration immediately before the glucose bolus was given, and (2) no differences in the IDVG values were observed with or without insulin infusions in the present study. In our previous study ${ }^{9}$ no consistent relationship was observed between the IDVG and plasma insulin concentrations during and after abdominal surgery. However, tracer techniques are required to determine the role of these modifications accurately.

Although all data in the present study were derived from uncontrolled critically ill patients, cardiac output can be grossly predicted by the IDVG $(r=0.89)$ without a thermodilution pulmonary catheter, and the IDVG can be predicted by only two plasma glucose determinations $(r=-0.94)$ : immediately before glucose is given and three minutes after the injection.

$\mathrm{We}^{10}$ reported that a relationship between the IDVG and cardiac output $(\mathrm{r}=0.65, P<0.05)$ was observed in a patient with phaeochromocytoma who showed marked haemodynamic instability during the peroperaive period with an excessive accumulation of fluids. In addition, during the period of the present study are patient who had obvious congestive heart failure showed decreases in cardiac output (2-3 L $\left.\cdot \mathrm{min}^{-1}\right)$ despite increases in the IDVG (6-7 L), and the patient was not included in the present study. Thus, we excluded post surgical patients as well as patients with apparent congestive heart failure from the present study. However, we could not convincingly demonstrate that patients in the present study did not have some fluid accumulation. Further study is required to examine the effect of fluid accumulation on the IDVG and cardiac output.

In conclusion, the present results indicate that the IDVG and thermodilution cardiac output in the critically ill vary markedly among patients, and support the hypothesis that the IDVG in patients, without obvious congestive heart failure, reflects cardiac output rather than glucose metabolism.

\section{Acknowledgements}

The authors wish to thank Professor Y. Tanaka (Kyoto, Japan), and Emeritus Professor J. McIntyre (Edmonton, Canada), Professor D. Grimaud (Nice, France) and Dr. E. Major (Swansea, UK) for their valuable comments, Y. Satoh for his technical assistance, and Miss M. Kudoh for her secretarial help.

\section{References}

1 Riggs DS. The mathematical approach to physiological problems: a critical primer. Cambridge, MA: MIT press, 1963.

2 Ghoneim M, Pearson K. Pharmacokinetics of drugs administered intravenously. In: Scurr C, Feldman S, Soni N (Eds). Scientific Foundations of Anaesthesia, 4th ed., Chicago: Year Book Medical Publishers, 1990: 559-71.

3 Bennet LZ, Sheiner LB. Pharmacokinetics: The dynamics of drug absorption, distribution, and elimination. In: Goodman Gilman A, Goodman LS, Rall TW, Murad F (Eds). The Pharmacological Basis of Therapeutics., New York: Macmillian Publishing Co., 1985: 3-34.

4 Yamaoka $K$, Tanigawara $Y$, Nakagawa T. Uno T. A pharmacokinetic analysis program (MULTI) for microcomputer. J Pharm Dyn 1981; 4: 879-85.

5 Cunningham VJ, Heath DF. An interpretation of the intravenous glucose tolerance test in the light of recent findings on the kinetics of glucose and insulin in man. Clin Sci Mol Med 1978; 54: 161-73.

6 Cobelli C, Bier DM, Ferrannini E. Modeling glucose metabolism in man: Theory and Practice. Horm Metab Res (Suppl) 1990; 24: 1-10.

7 Avram MJ, Krejcie TC, Henthorn TK. The relationship of age to the pharmacokinetics of early drug distribution: The concurrent disposition of thiopental and indocyanine green. Anesthesiology 1990; 72: 403-11.

8 Wick AN, Drury DR, Mackay EM. Glucose space of the body. Am J Physiol 1950; 163: 224-8.

9 Ishihara H, Tanioka F, Katagai $H$, et al. Effects of and surgery on glucose space in man. Jap J Anesth 1986; 35: 1057-60.

10 Ishihara H, Tanioka F, Isozaki $K$, Matsuki A, Oyama $T$. Postoperative management of diabetic patients in ICU. $I n$ : Matsuki A, Ishihara H, Oyama T (Eds). Endocrine Response to Anesthesia and Intensive Care. Amsterdam: Elsevier Science Publishers, 1990: 221-6. 